\title{
Efeitos do sexo, do grupo racial e da idade ao abate nas características de carcaça e maciez da carne de caprinos ${ }^{1}$
}

\author{
Jakilane Jacque Leal de Menezes ${ }^{2}$, Heraldo Cesar Gonçalves ${ }^{3}$, Marcela Silva Ribeiro², \\ Luciana Rodrigues ${ }^{2}$, Gil Ignacio Lara Cañizares ${ }^{2}$, Brenda Batista Lemos de Medeiros ${ }^{4}$
}

\footnotetext{
${ }^{1}$ Pesquisa financiada pela FAPESP.

2 Programa de Pós-Graduação em Zootecnia, FMVZ, UNESP, Botucatu- SP

${ }^{3}$ Departamento de Produção Animal, FMVZ, UNESP, Botucatu- SP.

${ }^{4}$ Curso de Zootecnia, FMVZ, UNESP, Botucatu- SP.
}

RESUMO - Este trabalho foi realizado com os objetivos de quantificar e qualificar a carcaça e os cortes cárneos de cabritos de dois sexos (machos e fêmeas) e três grupos raciais - Alpino; 1/2 Boer + 1/2 Alpino (1/2 BA); e 3/4 Boer + 1/4 Alpino (3/4 BA) - abatidos em três idades (aos 60, 90 e 120 dias de confinamento), visando avaliar o aproveitamento de cabritos provenientes de rebanhos leiteiros. As carcaças foram avaliadas pelas características de peso, rendimento, conformação, gordura de cobertura, comprimento interno e externo, comprimento da perna, perímetro da garupa, profundidade torácica, largura da garupa, compacidade, rendimento dos cortes cárneos e proporção dos tecidos. Os dados foram analisados em delineamento inteiramente casualizado, em esquema fatorial incompleto $2 \times 3 \times 3$ ( 2 sexos $\times 3$ grupos raciais $\times 3$ idades de abate). O aumento da idade dos animais promove aumento do peso e das medidas da carcaça, assim como dos componentes comestíveis da carcaça e do rendimento comercial. Mestiços Boer apresentam maior compacidade de perna e menos osso em relação aos Alpinos. O grupo racial, a idade de abate e o sexo não influenciam a maciez da carne.

Palavras-chave: compacidade, gordura, músculo, rendimento comercial

\section{Carcass and meat tenderness of goats according to age, breed group and age at slaughter}

\begin{abstract}
The objective of this experiment was to evaluate the yield and quality of the carcass and meat cuts from kids of both sexes, slaughtered at three different ages, aiming to use animals from dairy herds. Forty-one kids were used, from three breed groups: Alpine, $1 / 2$ Boer $1 / 2$ Alpine (1/2 BA) and 3/4 Boer 1/4 Alpine (3/4 BA), which were slaughtered at 60, 90 or 120 days of slaughter age. The animals were raised in a feedlot system. The following carcass traits were evaluated: carcass weight, commercial yield, conformation, subcutaneous fat, internal and external length, leg length, rump perimeter, thoracic depth, rump width, compactness, meat cut yield and tissue proportion. Meat tenderness was evaluated by means of the Warner-Bratzler shear force. Data were analyzed as an incomplete factorial arrangement ( 2 sexes $\times 3$ breed groups $\times 3$ slaughter ages), in a complete randomized design. As age increased, so did carcass weight and characteristics, as well as the weight of edible carcass components and commercial yield. The Boer crossbreds showed higher leg compactness and less bone compared to the Alpines. No difference in meat tenderness was observed for breed group, age or sex.
\end{abstract}

Key Words: commercial yield, compactness, fat, muscle

\section{Introdução}

A carcaça caprina apresenta baixo rendimento e é pouco compacta se comparada a outras espécies, porém tende a melhorar com o aumento de peso vivo (Madruga et al., 1999). Além disso, o rendimento é influenciado pela deposição de gordura, conformação e musculosidade da carcaça, idade e estado fisiológico e nutricional do animal. Cabritos machos da raça Saanen abatidos com 20 e 35 kg de peso vivo normalmente apresentam rendimento comercial de 43,7 e 47,3\% respectivamente (Yáñez et al., 2006).

O índice de compacidade da carcaça é uma medida indireta da conformação, obtida a partir da relação entre o peso e o comprimento da carcaça (Thwaites et al., 1964), e pode ser utilizado para avaliar a produção de músculo de animais com peso vivo semelhante (Simela et al., 1999). As carcaças mais pesadas, de diferentes grupos raciais apresentam maior índice de compacidade (Osório, 1992). 
Cabritos Saanen machos apresentam redução na proporção de perna e paleta e aumento na proporção do pescoço com o aumento do peso da carcaça (ColomerRocher etal., 1987). Odesenvolvimento do lombo acompanhou o crescimento da carcaça, considerado uma região de maturidade tardia (Pereira Filho, et al., 2008).

A qualidade da carne está relacionada à adequada distribuição das gorduras. A carcaça caprina tem uma fina camada de gordura subcutânea (1,6-2,2 mm), com notória influência dos grupos raciais. Grande parte da gordura corporal, em torno de 50 a $60 \%$, encontra-se depositada na cavidade abdominal, entre o abdômen e as vísceras, sendo a gordura subcutânea extremamente fina quando comparada à dos ovinos (Van Niekerk \& Casey, 1988). A gordura intermuscular tem crescimento mais precoce que a subcutânea (Pereira Filho, et al., 2008). Animais velhos tendem a possuir camada mais espessa de gordura e maior área de olho-de-lombo (Dhanda et al., 2003). As fêmeas também apresentaram maior deposição de gordura (13\%) em comparação aos machos (7,4\%) (Mahgoub et al., 2004).

A proporção de outros tecidos da carcaça (excluindo músculo, osso e gordura) diminui com a idade de abate (Todaro et al., 2002). O sexo e o estado fisiológico são fatores determinantes na proporção e locais de deposição dos tecidos e refletem na proporção dos cortes comerciais. O sexo tem maior influência no quarto dianteiro, uma vez que os machos desenvolvem mais os músculos, como Splenius, Longissimus capitis e Atlantis, e também maiores quantidade de osso (Johnson et al., 1995; Mahgoub et al., 2004). O aumento da idade contribui para a deposição de músculo na carcaça (Mahgoub \& Lodge, 1996; Todaro et al., 2002). Não foi observada influência do grupo racial na deposição de músculo na paleta (Oman et al., 1999; Oman et al., 2000).

A gordura intramuscular e o grau de gordura de cobertura na carcaça são fatores que contribuem para a suculência e maciez da carne. De maneira geral, a carne proveniente de animais jovens apresenta apenas traços de gordura; é macia, com aroma mais suave que o da carne de animais velhos, tornando-se atrativa aos consumidores (Silva Sobrinho, 2001).

A força de cisalhamento tem sido usada como forma de avaliação da maciez da carne. Johnson et al. (1995) observaram que o grupo racial não influencia na força de cisalhamento. Decréscimos em maciez e suculência com o avanço da idade foram relatados por alguns pesquisadores ao observarem que a carne de animais jovens apresentava-se mais suculenta que a de animais velhos (Schönfeldt et al.,1993; Madruga et al., 1999).
Este estudo foi realizado com o objetivo de avaliar as características quantitativas e qualitativas da carcaça e dos cortes cárneos de cabritos machos e fêmeas, de três grupos raciais, criados em confinamento e abatidos em três idades.

\section{Material e Métodos}

O experimento foi conduzido na Faculdade de Medicina Veterinária e Zootecnia, UNESP, Campus de Botucatu, Fazenda Lageado, na Área de Caprinocultura, utilizando-se 41 cabritos machos e fêmeas: 16 Alpinos, 14 1⁄2 BA e 113/4 BA. Parte dos animais foi abatida com média de 67,45 dias (P60), outra parte com 94,71 dias (P90) e o restante com 127,81 dias (P120).

Dos acasalamentos realizados para produção dos animais experimentais, verificou-se nascimento de poucas fêmeas. Além disso, as do grupo racial 1/2 BA, designadas ao abate com 60 dias, morreram, o que impossibilitou a avaliação de algumas interações (Tabela 1).

O aleitamento foi coletivo, feito artificialmente com leite de cabra e búfala, e fornecido em duas refeições diárias até o $7^{\circ}$ dia. A partir da segunda semana, foi realizado um aleitamento por dia, de manhã. Quando se utilizava leite de búfala, este era diluído com água na proporção de 1:1. A quantidade de leite oferecida diariamente não ultrapassou 1,5 L e o desmame foi realizado aos 60 dias.

A partir da segunda até a quarta semana, os cabritos tiveram à disposição concentrado farelado e pellets contendo $70 \%$ de concentrado e $30 \%$ de feno de coast cross. Os animais iniciaram o experimento com média de 32,85 dias, quando estavam recebendo somente a dieta peletizada, e foram alojados em nove baias coletivas de piso ripado e elevado, segundo a combinação grupo racial e idade de abate. A composição do concentrado utilizado foi: $49 \%$ de milho, $38 \%$ de farelo de soja, $10 \%$ de farelo de algodão, 2\% de calcário, 1\% de sal mineral. A composição bromatológica da dieta completa utilizada foi: matéria seca 90,33\%; proteína bruta, 13,85 \%; extrato etéreo, 4,54\%; fibra bruta, 13,50\%; fibra em detergente neutro, 27,79\%; e fibra em detergente ácido, 15,10\%. A ração foi calculada para atender às exigências em proteína bruta e energia metabolizável, segundo o NRC (1981).

O fornecimento da dieta sólida foi feito pela manhã. As sobras foram pesadas e ajustadas às quantidades fornecidas diariamente para permitir sobras de $15 \%$. Semanalmente foi avaliada a ingestão média de alimentos por baia, segundo o grupo racial e a idade de abate. Os animais tiveram à disposição água limpa e fresca. 
Tabela 1 - Número de animais utilizados, segundo a idade, o grupo racial e o sexo

\begin{tabular}{|c|c|c|c|c|c|c|}
\hline \multirow[b]{3}{*}{ Grupo racial } & \multicolumn{5}{|c|}{ Idade ao abate (dias) } & \\
\hline & \multicolumn{3}{|c|}{ Macho } & \multicolumn{3}{|c|}{ Fêmea } \\
\hline & 60 & 90 & 120 & 60 & 90 & 120 \\
\hline Alpino & 3 & 3 & 4 & 2 & 1 & 3 \\
\hline $1 / 2$ Boer & 3 & 3 & 2 & 0 & 3 & 3 \\
\hline $3 / 4$ Boer & 2 & 2 & 2 & 1 & 2 & 2 \\
\hline
\end{tabular}

Ao atingirem a idade de abate, os animais foram submetidos a um jejum de 24 horas, com acesso apenas à água. Em seguida, foram pesados, para determinação do peso vivo ao abate, e encaminhados ao Abatedouro comercial Don Pig, localizado na cidade de São Manuel, São Paulo.

Após a evisceração, as carcaças foram pesadas para obtenção do peso da carcaça quente e, após refrigeração a $4^{\circ} \mathrm{C}$ por um período de 24 horas foram novamente pesadas para obtenção do peso de carcaça fria.

O rendimento comercial da carcaça foi obtido pela relação entre o peso da carcaça fria e o peso vivo ao abate. A conformação da carcaça e a gordura de cobertura da carcaça foram determinadas subjetivamente por avaliação visual atribuindo-se notas de 1 a 5 . Para a conformação da carcaça, consideraram-se a carcaça como um todo, as diferentes regiões anatômicas e a espessura de seus planos musculares e adiposos em relação ao tamanho do esqueleto que a suporta, de modo que $1=$ muito pobre e 5 = excelente. $\mathrm{Na}$ avaliação gordura de cobertura da carcaça, foram observadas a extensão da cobertura de gordura e sua espessura, atribuindo-se 1 para excessivamente magra e 5 gorda.

Com o auxílio de uma fita métrica, foram feitas as seguintes medidas: comprimento externo da carcaça, comprimento interno da carcaça, comprimento da perna, largura da garupa, perímetro da garupa e profundidade do tórax.

Foram calculados o índice de compacidade da carcaça, com relação entre o peso da carcaça fria e o comprimento interno da carcaça; e o índice de compacidade da perna, como a relação entre a largura da garupa e o comprimento da perna.

Após o resfriamento, a carcaça foi dividida ao meio, obtendo-se a meia-carcaça e seccionada em sete regiões anatômicas, para obtenção dos seguintes cortes cárneos: pescoço, paleta, costelas descobertas, costela, lombo, perna e baixos. Esses cortes foram sempre realizados na metade direita da carcaça. A área de olho-de-lombo, em $\mathrm{cm}^{2}$, foi medida com a metodologia da grade de pontos.
A paleta e o lombo foram dissecados para determinar as quantidades de tecido ósseo, muscular, adiposo (subdividido em gordura subcutânea e intermuscular), conjuntivo e outros (linfonodos, nervos, vasos sanguíneos, tendões, etc.). No lombo ainda foram determinados o peso do Longissimus dorsi, gordura perirrenal e espessura de gordura.

Os dados experimentais foram analisados em esquema fatorial incompleto, 2 sexos $\times 3$ grupos raciais $\times 3$ idades, em delineamento inteiramente casualizado por meio de Análise de Variância utilizando-se o modelo 1. Como algumas combinações das fontes de variação não tiveram observações e outras repetições foram insuficientes (Tabela 1), as interações sexo $\times$ grupo racial, sexo $\times$ idade e sexo $\times$ grupo racial $\times$ idade não foram incluídas no modelo de análise. Para comparação entre médias de grupo racial e idade de abate, foi utilizado o teste de Tukey $(\mathrm{P}<0,05)$. As análises foram processadas utilizando-se o SAEG - Sistema de Análises Estatísticas e Genéticas (UFV, 2000).

Modelo 1

$\mathrm{Y}_{\mathrm{ijkl}}=\mathrm{u}+\mathrm{S}_{\mathrm{i}}+\mathrm{I}_{\mathrm{j}}+\mathrm{GR}_{\mathrm{k}}+\left(\mathrm{I}^{*} \mathrm{GR}\right)_{\mathrm{jk}}+\mathrm{e}_{\mathrm{ijkl}}$,

em que: $\mathrm{Y}_{\mathrm{ijkl}}=$ característica observada no animal l, do sexo $\mathrm{i}$, do grupo racial $\mathrm{k}$ e abatido na idade $\mathrm{j} ; \mathrm{u}=$ constante inerente aos dados; $\mathrm{S}_{\mathrm{i}}=$ efeito do sexo $\mathrm{i}$, de modo que $\mathrm{i}=1$ : macho e 2: fêmea; $I_{j}=$ efeito da idade de abate $j$, em que: $j=1$ : 60 dias, 2: 90 dias e 3: 120 dias; $\mathrm{GR}_{\mathrm{k}}=$ efeito do grupo racial k, em que $\mathrm{k}=1$ : Alpina, $2: 1 / 2 \mathrm{BA}$ e $3: 3 / 4 \mathrm{BA} ; \mathrm{I}^{*} \mathrm{GR}_{\mathrm{jk}}=$ efeito da interação idade de abate $\mathrm{j} \times$ grupo racial $\mathrm{k}$; $\mathrm{e}_{\mathrm{ijkl}}$, = erro associado à informação $\mathrm{Y}_{\mathrm{ijkl}} \sim \operatorname{NID}\left(0 ; \sigma^{2}{ }_{\mathrm{e}}\right)$.

Para a avaliação da maciez, foi utilizado o músculo Longissimus dorsi, que foi identificado, envolto em papel-alumínio, colocado em saco plástico e congelado. Após o descongelamento, foram colhidas duas amostras de cada animal com uma média de $1,5 \mathrm{~cm}$ e pesadas em balança analítica. As amostras foram posicionadas em saco plástico e levadas ao banho-maria a $75^{\circ} \mathrm{C}$ por 1 hora. Depois, foram então retiradas e secas em papel toalha. As amostras foram cortadas perpendicularmente à orientação das fibras musculares e em seguida foi calculada a força de cisalhamento por meio do aparelho Warner-Bratzler shear force.

\section{Resultados e Discussão}

O peso vivo ao abate (PVA) e todas as outras características de carcaça foram influenciados pela idade de abate, com exceção da profundidade do tórax (Tabela 2). Os valores dessas características, de modo geral, aumentaram com a idade de abate. $\mathrm{O}$ aumento linear pode ser entendido como resposta ao crescimento dos animais refletindo em 
aumento das médias dessas características, semelhante ao encontrado por Mahgoub \& Lu (1998), Todaro et al. (2002) e Pereira Filho et al. (2008).

A gordura de cobertura da carcaça foi afetada pela idade ao abate. A quantidade de gordura nos animais abatidos aos 60 dias foi maior que naqueles abatidos aos 90 dias e não diferiu da observada nos animais abatidos aos 120 dias. A menor quantidade de gordura observada nos animais abatidos aos 90 dias pode ser reflexo do desmame aos 60 dias, em decorrência do estresse do desaleitamento e da adaptação à dieta unicamente sólida.

O rendimento comercial da carcaça foi maior aos 120 dias, com média de até $51,62 \%$, maior que a encontrada por Yáñez et al. (2006) em caprinos da raça Saanen. Os rendimentos não diferiram entre os animais abatidos aos 60 e aos 90 dias. Como o rendimento comercial de carcaça melhora com o aumento do peso ao abate (Madruga et al., 1999), esperar-se-ia maior valor nos animais abatidos aos 90 dias em comparação àqueles abatidos aos 60 dias, o que não foi observado, possivelmente em virtude do estresse provocado pelo desaleitamento imposto por volta dos 60 dias.

O grupo racial influenciou o comprimento externo da carcaça, que foi maior nos Alpinos em comparação aos mestiços, e o comprimento da perna, que foi maior nos Alpinos em comparação anos $3 / 4 \mathrm{BA}$, que não diferiram dos $1 / 2 \mathrm{BA}$, o que indica redução com o aumento da participação da raça Boer. Em pesquisa com os mesmos animais, Menezes et al. (2007) relataram que os Alpinos apresentaram medidas biométricas maiores para comprimento do corpo e altura posterior, característica de caprinos leiteiros, que pode explicar o maior comprimento externo da carcaça e o comprimento da perna. Também não foi observada diferença de peso vivo ao abate e peso da carcaça quente entre os grupos raciais, o que difere dos resultados encontrados por Goonewardene et al. (1998), que verificaram maior peso ao abate e peso da carcaça quente em Alpinos, mestiços Boer $\times$ Alpino e Alpino $\times$ Spanish em comparação aos Boer $\times$ Spanhish. Dhanda et al. (1999) também obtiveram maior média de peso vivo ao abate em mestiços Boer $\times$ Saanen em relação aos outros grupos raciais. Os machos apresentaram maior peso vivo ao abate, que acabou influenciando outras características, como peso da carcaça quente, peso da carcaça fria, comprimento interno da carcaça e perímetro da garupa, similar aos resultados descritos por Johnson et al. (1995) e Mahgoub \& Lu (1998).

O comprimento interno da carcaça foi influenciado pela interação grupo racial $\times$ idade. Nas idades de abate de 90 e 120 dias, não houve diferença entre os grupos raciais, ao passo que, aos 60 dias, os Alpinos apresentaram maior comprimento interno da carcaça em comparação aos mestiços (Tabela 3).

O comprimento interno da carcaça nos Alpinos foi menor aos 60 dias e não diferiu entre as idades de 90 e 120 dias ao abate. Nos animais $1 \frac{1}{2}$ Boer, o comprimento interno da carcaça aumentou com a idade de abate e nos $3 / 4$ Boer os valores foram semelhantes aos 60 e 90 dias e menores que aos 120 dias.

Os cortes da carcaça: paleta, perna, costela descoberta, costela, lombo, pescoço e baixos aumentaram com a idade de abate (Tabela 4), apresentando comportamento semelhante ao do peso da carcaça quente e fria. Não foi observada influência do grupo racial nos cortes da carcaça, o que difere dos relatos de Kadim et al. (2003). O índice de compacidade da carcaça não diferiu aos 60 e 90 dias e foram menores que aos 120 dias. Como o índice de compacidade da carcaça é obtido pela relação entre o peso da carcaça fria e o comprimento interno da carcaça, esse aumento pode ter sido ocasionado pela maior deposição de tecido na carcaça em relação ao aumento do comprimento interno da carcaça. O índice de compacidade da perna foi maior aos 120 que aos 90 dias de idade, mas não diferiu da média obtida aos 60 dias. O mesmo foi observado para o rendimento comercial da carcaça, uma vez que o desaleitamento pode ter afetado as características de compacidade aos 90 dias.

O grupo racial influenciou o índice de compacidade da perna, que aumentou com o grau de sangue Boer, possivelmente em razão de sua menor estatura ou do maior comprimento de perna observado para os Alpinos.

A área de olho-de-lombo aumentou com a idade de abate, mas não diferiu entre as idades de 90 e 120 dias ao abate, acompanhando o crescimento do lombo e do músculo Longissimus dorsi, o mesmo observado por Bueno et al. (1997) e Dhanda et al. (2003). Não foi observada influência do grupo racial na área de olho-de-lombo, o que difere dos resultados encontrados por Amin et al. (2000).

Os machos apresentaram maiores valores para paleta, perna, costela descoberta, lombo, pescoço, baixos, índice de compacidade da carcaça e área de olho-delombo (Tabela 4), o que pode ter sido ocasionado pela superioridade do peso vivo ao abate, peso da carcaça quente e peso da carcaça fria dos machos em relação às fêmeas. O grupo racial e o sexo não influenciaram as demais características estudadas.

O percentual de costela descoberta e lombo foi maior aos 120 dias (Tabela 5). A menor porcentagem obtida para esses cortes foi observada aos 90 dias, provavelmente em virtude do desmame aos 60 dias. O percentual de pescoço foi maior aos 90 que aos 120 dias, que não diferiu do percentual aos 60 dias. 
A porcentagem de perna foi influenciada pela interação grupo racial $\times$ idade; os Alpinos apresentaram a mesma porcentagem de perna nas três épocas de abate, enquanto os mestiços apresentaram menor porcentagem de perna aos 120 dias em relação aos 60 e 90 dias. Com o aumento da idade, a porcentagem de perna diminuiu, confirmando observações de Colomer-Rocher et al. (1987), porém foi menor nos Alpinos aos 60 dias e ficou maior que a dos 3/4 BA aos 120 dias (Tabela 6). Essas observações indicam que, com o avançar da idade, o percentual de costela e lombo aumenta e que o percentual de pescoço e perna diminui.

As composições médias de paleta e lombo após o descongelamento foram de 0,98 e 0,34 kg, respectivamente (Tabelas 7 e 8). A quantidade de músculo da paleta apresentou o mesmo comportamento da paleta - aumentou com a idade de abate dos animais -, confirmando observações de Mahgoub \& Lodge (1996) e Todaro et al. (2002). Os valores obtidos para os machos foram maiores que para as fêmeas que também apresentaram carcaças mais pesadas.

O grupo racial não influenciou as quantidades de músculo e osso da paleta, o que está de acordo com relatos de Oman et al. (1999) e Oman et al. (2000). Os valores de gordura intermuscular da paleta e osso da paleta maiores valores aos 120 que aos 60 e 90 dias, que não diferiram entre si e acompanharam o aumento de peso da carcaça.

Não foi observada influência do grupo racial na gordura subcutânea e intermuscular da paleta, o que confirma resultados observados por Oman et al. (1999) e

Tabela 2 - Características de peso vivo, medidas e rendimento comercial da carcaça de cabritos de três grupos raciais e dois sexos abatidos em três idades

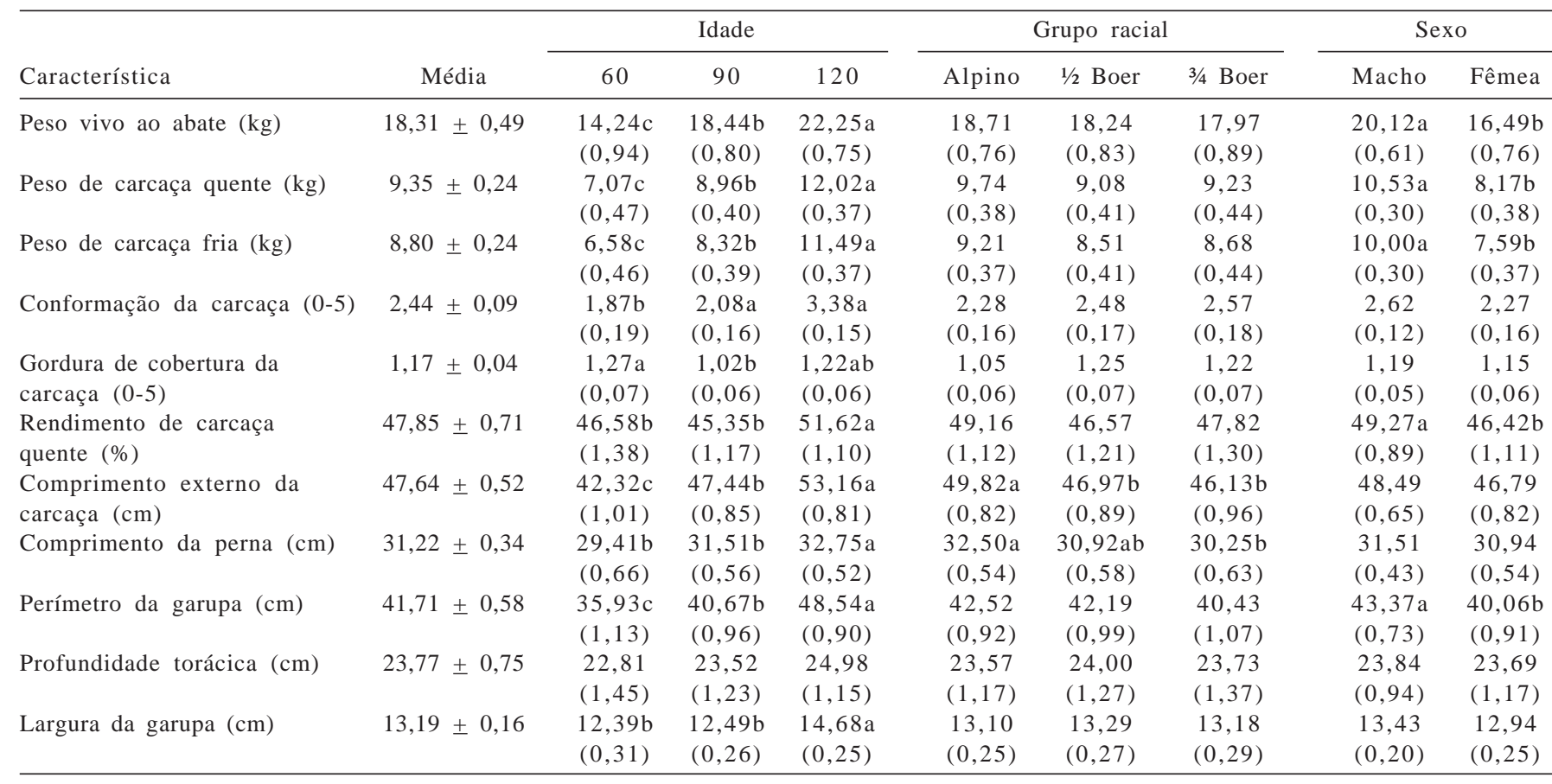

Para cada fonte de variação, médias seguidas de mesma letra não diferem $(P<0,05)$ entre si.

Tabela 3 - Comprimento interno da carcaça de cabritos machos e fêmeas de três grupos raciais abatidos em diversas idades

\begin{tabular}{|c|c|c|c|c|c|c|c|}
\hline \multirow[b]{2}{*}{ Característica } & \multirow[b]{2}{*}{ Média } & \multirow[b]{2}{*}{ Idade } & \multicolumn{3}{|c|}{ Grupo racial } & \multicolumn{2}{|c|}{ Sexo } \\
\hline & & & Alpino & $1 / 2$ Boer & $3 / 4$ Boer & Macho & Fêmea \\
\hline \multirow[t]{3}{*}{ Comprimento interno da carcaça } & $\begin{array}{l}45,40 \\
(0,40)\end{array}$ & 60 & $\begin{array}{c}44,41 \mathrm{Ab} \\
(1,08)\end{array}$ & $\begin{array}{c}39,36 \mathrm{Bc} \\
(1,45)\end{array}$ & $\begin{array}{c}39,01 \mathrm{Bb} \\
(1,39)\end{array}$ & $\begin{array}{l}46,37 a \\
(0,50)\end{array}$ & $\begin{array}{l}44,43 b \\
(0,63)\end{array}$ \\
\hline & & 90 & $\begin{array}{c}47,01 \mathrm{Aa} \\
(1,22)\end{array}$ & $\begin{array}{c}45,00 \mathrm{Ab} \\
(0,98)\end{array}$ & $\begin{array}{c}43,00 \mathrm{Ab} \\
(1,20)\end{array}$ & & \\
\hline & & 120 & $\begin{array}{c}49,86 \mathrm{Aa} \\
(0,91)\end{array}$ & $\begin{array}{c}50,19 \mathrm{Aa} \\
(1,08)\end{array}$ & $\begin{array}{c}50,75 \mathrm{Aa} \\
(1,20)\end{array}$ & & \\
\hline
\end{tabular}

Para os níveis de idade, médias seguidas de mesma letra maiúscula não diferem entre si para os grupos raciais.

Para os grupos raciais, médias seguidas de mesma letra minúscula não diferem $(P<0,05)$ entre si para as idades. 
Oman et al. (2000). O tecido conjuntivo e outros tecidos da paleta não diferiram entre 90 e 120 dias e foram maior aos 60 dias, discordando dos relatos de Todaro et al. (2002) de que, com o aumento da idade, diminui o percentual de outros tecidos da carcaça.

O lombo e seus tecidos: músculo, gordura subcutânea, gordura intermuscular, tecido conjuntivo e gordura renal (Tabela 7) apresentaram o mesmo comportamento, aumentando com o avançar da idade de abate, acompanhando o crescimento e o aumento de peso da carcaça (Tabela 2). As médias aos 60 e 90 dias, no entanto, não apresentaram diferença entre si, o que está de acordo com o observado por Dhanda et al. (1999). Comportamento semelhante foi constatado para osso do lombo e o músculo Longissimus dorsi, com médias diferentes para todas as idades.

O grupo racial influenciou de maneira semelhante o lombo, o osso e outros tecidos do lombo, que foram maiores nos Alpinos em comparação aos 3/4 Boer (ambos não diferiram dos $1 \frac{1}{2}$ Boer). O maior peso do lombo nos Alpinos pode estar relacionado ao maior comprimento externo e interno de carcaça em relação aos mestiços e possivelmente aumentou o comprimento do lombo nesse

Tabela 4 - Características da carcaça, compacidade e área de olho-de-lombo de cabritos machos e fêmeas de três grupos raciais abatidos em diversas idades

\begin{tabular}{|c|c|c|c|c|c|c|c|c|c|}
\hline \multirow[t]{2}{*}{ Característica } & \multirow[t]{2}{*}{ Média } & \multicolumn{3}{|c|}{ Idade } & \multicolumn{3}{|c|}{ Grupo racial } & \multicolumn{2}{|c|}{ Sexo } \\
\hline & & 60 & 90 & 120 & Alpino & $1 / 2$ Boer & $3 / 4$ Boer & Macho & Fêmea \\
\hline Paleta (kg) & $\begin{array}{c}1,00 \\
(0,02)\end{array}$ & $\begin{array}{c}0,73 c \\
(0,05)\end{array}$ & $\begin{array}{c}0,97 \mathrm{~b} \\
(0,05)\end{array}$ & $\begin{array}{l}1,31 \mathrm{a} \\
(0,04)\end{array}$ & $\begin{array}{c}1,05 \\
(0,04)\end{array}$ & $\begin{array}{c}0,98 \\
(0,05)\end{array}$ & $\begin{array}{c}0,97 \\
(0,05)\end{array}$ & $\begin{array}{l}1,13 \mathrm{a} \\
(0,03)\end{array}$ & $\begin{array}{c}0,87 b \\
(0,04)\end{array}$ \\
\hline Perna (kg) & $\begin{array}{c}1,35 \\
(0,03)\end{array}$ & $\begin{array}{l}1,04 c \\
(0,06)\end{array}$ & $\begin{array}{l}1,30 \mathrm{~b} \\
(0,05)\end{array}$ & $\begin{array}{l}1,71 \mathrm{a} \\
(0,05)\end{array}$ & $\begin{array}{c}1,40 \\
(0,05)\end{array}$ & $\begin{array}{c}1,34 \\
(0,05)\end{array}$ & $\begin{array}{c}1,31 \\
(0,06)\end{array}$ & $\begin{array}{l}1,50 \mathrm{a} \\
(0,04)\end{array}$ & $\begin{array}{l}1,20 \mathrm{~b} \\
(0,05)\end{array}$ \\
\hline Costela descoberta (kg) & $\begin{array}{c}0,24 \\
(0,01)\end{array}$ & $\begin{array}{l}0,16 \mathrm{~b} \\
(0,03)\end{array}$ & $\begin{array}{l}0,19 b \\
(0,02)\end{array}$ & $\begin{array}{c}0,38 a \\
(0,02)\end{array}$ & $\begin{array}{c}0,28 \\
(0,02)\end{array}$ & $\begin{array}{c}0,21 \\
(0,02)\end{array}$ & $\begin{array}{c}0,23 \\
(0,03)\end{array}$ & $\begin{array}{l}0,29 a \\
(0,02)\end{array}$ & $\begin{array}{c}0,18 \mathrm{~b} \\
(0,02)\end{array}$ \\
\hline Costela (kg) & $\begin{array}{c}0,38 \\
(0,01)\end{array}$ & $\begin{array}{l}0,28 \mathrm{~b} \\
(0,03)\end{array}$ & $\begin{array}{l}0,34 \mathrm{~b} \\
(0,02)\end{array}$ & $\begin{array}{c}0,52 \mathrm{a} \\
(0,02)\end{array}$ & $\begin{array}{c}0,38 \\
(0,02)\end{array}$ & $\begin{array}{c}0,36 \\
(0,02)\end{array}$ & $\begin{array}{c}0,39 \\
(0,03)\end{array}$ & $\begin{array}{c}0,41 \\
(0,02)\end{array}$ & $\begin{array}{c}0,35 \\
(0,02)\end{array}$ \\
\hline Lombo (kg) & $\begin{array}{c}0,37 \\
(0,01)\end{array}$ & $\begin{array}{c}0,26 \mathrm{~b} \\
(0,02)\end{array}$ & $\begin{array}{c}0,32 \mathrm{~b} \\
(0,02)\end{array}$ & $\begin{array}{c}0,52 \mathrm{a} \\
(0,01)\end{array}$ & $\begin{array}{c}0,41 \\
(0,02)\end{array}$ & $\begin{array}{c}0,36 \\
(0,02)\end{array}$ & $\begin{array}{c}0,34 \\
(0,02)\end{array}$ & $\begin{array}{c}0,40 a \\
(0,01)\end{array}$ & $\begin{array}{c}0,34 \mathrm{~b} \\
(0,02)\end{array}$ \\
\hline Pescoço (kg) & $\begin{array}{c}0,36 \\
(0,01)\end{array}$ & $\begin{array}{c}0,27 c \\
(0,02)\end{array}$ & $\begin{array}{l}0,36 \mathrm{~b} \\
(0,02)\end{array}$ & $\begin{array}{l}0,44 a \\
(0,02)\end{array}$ & $\begin{array}{c}0,34 \\
(0,02)\end{array}$ & $\begin{array}{c}0,35 \\
(0,02)\end{array}$ & $\begin{array}{c}0,37 \\
(0,02)\end{array}$ & $\begin{array}{l}0,41 \mathrm{a} \\
(0,02)\end{array}$ & $\begin{array}{c}0,30 \mathrm{~b} \\
(0,02)\end{array}$ \\
\hline Baixos (kg) & $\begin{array}{c}0,63 \\
(0,02)\end{array}$ & $\begin{array}{l}0,43 \text { c } \\
(0,04)\end{array}$ & $\begin{array}{c}0,58 b \\
(0,04)\end{array}$ & $\begin{array}{c}0,88 a \\
(0,03)\end{array}$ & $\begin{array}{c}0,63 \\
(0,06)\end{array}$ & $\begin{array}{c}0,61 \\
(0,04)\end{array}$ & $\begin{array}{c}0,65 \\
(0,04)\end{array}$ & $\begin{array}{c}0,72 a \\
(0,03)\end{array}$ & $\begin{array}{l}0,54 \mathrm{~b} \\
(0,03)\end{array}$ \\
\hline $\begin{array}{l}\text { Índice de compacidade da } \\
\text { carcaça }(\mathrm{kg} / \mathrm{cm})\end{array}$ & $\begin{array}{l}0,191 \\
(0,04)\end{array}$ & $\begin{array}{l}0,161 b \\
(0,08)\end{array}$ & $\begin{array}{l}0,184 \mathrm{~b} \\
(0,07)\end{array}$ & $\begin{array}{l}0,228 \mathrm{a} \\
(0,07)\end{array}$ & $\begin{array}{l}0,194 \\
(0,07)\end{array}$ & $\begin{array}{l}0,187 \\
(0,07)\end{array}$ & $\begin{array}{l}0,191 \\
(0,08)\end{array}$ & $\begin{array}{l}0,213 a \\
(0,05)\end{array}$ & $\begin{array}{l}0,169 b \\
(0,07)\end{array}$ \\
\hline Índice de compacidade da perna & $\begin{array}{c}0,424 \\
(0,005)\end{array}$ & $\begin{array}{c}0,424 \mathrm{ab} \\
(0,01)\end{array}$ & $\begin{array}{l}0,397 \mathrm{~b} \\
(0,008)\end{array}$ & $\begin{array}{l}0,450 \mathrm{a} \\
(0,008)\end{array}$ & $\begin{array}{l}0,403 \mathrm{~b} \\
(0,008)\end{array}$ & $\begin{array}{l}0,429 a b \\
(0,009)\end{array}$ & $\begin{array}{l}0,438 \mathrm{a} \\
(0,009)\end{array}$ & $\begin{array}{c}0,427 \\
(0,006)\end{array}$ & $\begin{array}{c}0,419 \\
(0,008)\end{array}$ \\
\hline Área de olho-de-lombo $\left(\mathrm{cm}^{2}\right)$ & $\begin{array}{l}7,57 \\
(0,31)\end{array}$ & $\begin{array}{l}5,89 \mathrm{~b} \\
(0,60)\end{array}$ & $\begin{array}{l}7,83 a \\
(0,51)\end{array}$ & $\begin{array}{l}8,98 \mathrm{a} \\
(0,48)\end{array}$ & $\begin{array}{c}7,22 \\
(0,49)\end{array}$ & $\begin{array}{c}7,28 \\
(0,53)\end{array}$ & $\begin{array}{c}8,19 \\
(0,58)\end{array}$ & $\begin{array}{l}8,38 \mathrm{a} \\
(0,39)\end{array}$ & $\begin{array}{l}6,75 b \\
(0,49)\end{array}$ \\
\hline
\end{tabular}

Para cada fonte de variação, médias seguidas de mesma letra não diferem $(P<0,05)$ entre si.

Tabela 5 - Porcentagem dos cortes da carcaça de cabritos machos e fêmeas de três grupos raciais abatidos em diversas idades

\begin{tabular}{|c|c|c|c|c|c|c|c|c|c|}
\hline \multirow[t]{2}{*}{ Característica } & \multirow[t]{2}{*}{ Média } & \multicolumn{3}{|c|}{ Idade } & \multicolumn{3}{|c|}{ Grupo racial } & \multicolumn{2}{|c|}{ Sexo } \\
\hline & & 60 & 90 & 120 & Alpino & $1 / 2$ Boer & $3 / 4$ Boer & Macho & Fêmea \\
\hline Paleta, \% & $\begin{array}{l}23,21 \\
(0,21)\end{array}$ & $\begin{array}{l}23,10 \\
(0,40)\end{array}$ & $\begin{array}{l}23,79 \\
(0,34)\end{array}$ & $\begin{array}{l}22,64 \\
(0,32)\end{array}$ & $\begin{array}{l}23,39 \\
(0,33)\end{array}$ & $\begin{array}{l}23,45 \\
(0,35)\end{array}$ & $\begin{array}{l}22,70 \\
(0,38)\end{array}$ & $\begin{array}{l}23,26 \\
(0,26)\end{array}$ & $\begin{array}{l}23,09 \\
(0,32)\end{array}$ \\
\hline Costela descoberta, \% & $\begin{array}{c}5,46 \\
(0,30)\end{array}$ & $\begin{array}{l}5,18 a b \\
(0,58)\end{array}$ & $\begin{array}{c}4,71 b \\
(0,50)\end{array}$ & $\begin{array}{l}6,49 a \\
(0,47)\end{array}$ & $\begin{array}{c}6,15 \\
(0,47)\end{array}$ & $\begin{array}{c}4,87 \\
(0,51)\end{array}$ & $\begin{array}{c}5,35 \\
(0,55)\end{array}$ & $\begin{array}{c}5,87 \\
(0,38)\end{array}$ & $\begin{array}{c}5,04 \\
(0,47)\end{array}$ \\
\hline Costela, \% & $\begin{array}{c}8,60 \\
(0,20)\end{array}$ & $\begin{array}{c}8,72 \\
(0,39)\end{array}$ & $\begin{array}{c}8,25 \\
(0,34)\end{array}$ & $\begin{array}{c}9,08 \\
(0,31)\end{array}$ & $\begin{array}{c}8,41 \\
(0,32)\end{array}$ & $\begin{array}{c}8,59 \\
(0,35)\end{array}$ & $\begin{array}{c}9,05 \\
(0,37)\end{array}$ & $\begin{array}{c}8,40 \\
(0,25)\end{array}$ & $\begin{array}{c}8,97 \\
(0,32)\end{array}$ \\
\hline Pescoço, \% & $\begin{array}{c}8,19 \\
(0,18)\end{array}$ & $\begin{array}{l}8.20 \mathrm{ab} \\
(0,35)\end{array}$ & $\begin{array}{c}8.90 \mathrm{a} \\
(0,30)\end{array}$ & $\begin{array}{l}7,62 \mathrm{~b} \\
(0,28)\end{array}$ & $\begin{array}{c}7,69 \\
(0,29)\end{array}$ & $\begin{array}{c}8,29 \\
(0,31)\end{array}$ & $\begin{array}{c}8,74 \\
(0,34)\end{array}$ & $\begin{array}{c}8,43 \\
(0,23)\end{array}$ & $\begin{array}{c}8,05 \\
(0,29)\end{array}$ \\
\hline Baixos, \% & $\begin{array}{c}14,48 \\
(0,30)\end{array}$ & $\begin{array}{l}13,58 \\
(0,59)\end{array}$ & $\begin{array}{l}14,28 \\
(0,50)\end{array}$ & $\begin{array}{l}15,32 \\
(0,47)\end{array}$ & $\begin{array}{c}14,06 \\
(0,48)\end{array}$ & $\begin{array}{l}14,17 \\
(0,51)\end{array}$ & $\begin{array}{l}14,94 \\
(0,56)\end{array}$ & $\begin{array}{l}14,76 \\
(0,37)\end{array}$ & $\begin{array}{c}14,03 \\
(0,47)\end{array}$ \\
\hline
\end{tabular}

Para cada fonte de variação, médias seguidas de mesma letra não diferem $(\mathrm{P}<0,05)$ entre si. 
grupo racial, em decorrência da maior quantidade de osso e outros tecidos, resultado que se assemelha ao encontrado por Johnson et al. (1995).

Geralmente na espécie caprina a quantidade de gordura de cobertura é escassa. Neste estudo, a média da espessura de gordura do lombo foi de $0,94 \mathrm{~mm}$ (Tabela 7), inferior ao obtida por Van Niekerk \& Casey (1998), de 1,6-2,2 mm. A proporção dos tecidos da paleta foi de 58,90; 1,26; 8,98; 4,54; 20,04 e 2,49\% para músculo, gordura subcutânea, gordura intermuscular, tecido conjuntivo, osso e outros tecidos, respectivamente (Tabela 8).

A proporção de tecidos do lombo foi de 58,93; 15,99; 3,28; 4,31; 7,82; 16,13 e 2,65\% para músculo + Longissimus dorsi, gordura subcutânea, gordura intermuscular, tecido

Tabela 6 - Porcentagem de perna de cabritos machos e fêmeas de três grupos raciais abatidos em diversas idades

\begin{tabular}{|c|c|c|c|c|c|c|c|}
\hline \multirow[b]{2}{*}{ Característica } & \multirow[b]{2}{*}{ Média } & \multirow[b]{2}{*}{ Idade } & \multicolumn{3}{|c|}{ Grupo racial } & \multicolumn{2}{|c|}{ Sexo } \\
\hline & & & Alpino & $1 / 2$ Boer & $3 / 4$ Boer & Macho & Fêmea \\
\hline \multirow[t]{3}{*}{ Perna \% } & $\begin{array}{c}31,59 \\
(0,23)\end{array}$ & 60 & $\begin{array}{c}31,39 \mathrm{Ba} \\
(0,62)\end{array}$ & $\begin{array}{c}34,46 \mathrm{Aa} \\
(0,84)\end{array}$ & $\begin{array}{c}33,52 \mathrm{Aa} \\
(0,81)\end{array}$ & $\begin{array}{c}31,13 \\
(0,29)\end{array}$ & $\begin{array}{l}32,07 \\
(0,36)\end{array}$ \\
\hline & & 90 & $\begin{array}{c}32,34 \mathrm{Aa} \\
(0,71)\end{array}$ & $\begin{array}{c}32,37 \mathrm{Aa} \\
(0,57)\end{array}$ & $\begin{array}{c}31,36 \mathrm{Aa} \\
(0,70)\end{array}$ & & \\
\hline & & 120 & $\begin{array}{c}30,51 \mathrm{Aa} \\
(0,53)\end{array}$ & $\begin{array}{c}29,81 \mathrm{Ab} \\
(0,63)\end{array}$ & $\begin{array}{c}28,82 \mathrm{Bb} \\
(0,70)\end{array}$ & & \\
\hline
\end{tabular}

Para os níveis de idade, médias seguidas de mesma letra maiúscula não diferem entre si para os grupos raciais.

Para os grupos raciais, médias seguidas de mesma letra minúscula não diferem $(\mathrm{P}<0,05)$ entre si para as idades.

Tabela 7 - Composição tecidual da paleta e do lombo de cabritos machos e fêmeas de três grupos raciais abatidos em diversas idades

\begin{tabular}{|c|c|c|c|c|c|c|c|c|c|}
\hline \multirow{3}{*}{ Composição da paleta } & \multirow[b]{2}{*}{ Média } & \multicolumn{3}{|c|}{ Idade } & \multicolumn{3}{|c|}{ Grupo racial } & \multicolumn{2}{|c|}{ Sexo } \\
\hline & & \multirow[t]{2}{*}{60} & \multirow[t]{2}{*}{90} & \multirow[t]{2}{*}{120} & \multirow[t]{2}{*}{ Alpino } & \multirow[t]{2}{*}{$1 / 2$ Boer } & \multirow[t]{2}{*}{$3 / 4$ Boer } & \multirow[t]{2}{*}{ Macho } & \multirow[t]{2}{*}{ Fêmea } \\
\hline & & & & & & & & & \\
\hline Paleta (kg) & $\begin{array}{c}0,98 \\
(0,027)\end{array}$ & $\begin{array}{c}0,72 \mathrm{c} \\
(0,053)\end{array}$ & $\begin{array}{c}0,95 b \\
(0,045)\end{array}$ & $\begin{array}{c}1,28 \mathrm{a} \\
(0,042)\end{array}$ & $\begin{array}{c}1,03 \\
(0,043)\end{array}$ & $\begin{array}{c}0,96 \\
(0,046)\end{array}$ & $\begin{array}{c}0,96 \\
(0,050)\end{array}$ & $\begin{array}{c}1,12 \mathrm{a} \\
(0,034)\end{array}$ & $\begin{array}{c}0,85 b \\
(0,042)\end{array}$ \\
\hline Músculo (kg) & $\begin{array}{c}0,58 \\
(0,017)\end{array}$ & $\begin{array}{c}0,41 \mathrm{c} \\
(0,033)\end{array}$ & $\begin{array}{c}0,54 b \\
(0,028)\end{array}$ & $\begin{array}{c}0,79 a \\
(0,026)\end{array}$ & $\begin{array}{c}0,60 \\
(0,027)\end{array}$ & $\begin{array}{c}0,57 \\
(0,029)\end{array}$ & $\begin{array}{c}0,57 \\
(0,031)\end{array}$ & $\begin{array}{c}0,66 a \\
(0,021)\end{array}$ & $\begin{array}{c}0,49 b \\
(0,027)\end{array}$ \\
\hline Gordura subcutânea (kg) & $\begin{array}{c}0,012 \\
(0,001)\end{array}$ & $\begin{array}{c}0,013 \\
(0,002)\end{array}$ & $\begin{array}{l}0,0095 \\
(0,001)\end{array}$ & $\begin{array}{l}0,0139 \\
(0,002)\end{array}$ & $\begin{array}{c}0,012 \\
(0,002)\end{array}$ & $\begin{array}{c}0,014 \\
(0,002)\end{array}$ & $\begin{array}{c}0,011 \\
(0,002)\end{array}$ & $\begin{array}{c}0,014 \\
(0,001)\end{array}$ & $\begin{array}{c}0,010 \\
(0,002)\end{array}$ \\
\hline Gordura intermuscular (kg) & $\begin{array}{c}0,091 \\
(0,005)\end{array}$ & $\begin{array}{c}0,056 b \\
(0,005)\end{array}$ & $\begin{array}{c}0,087 b \\
(0,009)\end{array}$ & $\begin{array}{c}0,129 a \\
(0,008)\end{array}$ & $\begin{array}{c}0,085 \\
(0,008)\end{array}$ & $\begin{array}{c}0,090 \\
(0,008)\end{array}$ & $\begin{array}{c}0,098 \\
(0,008)\end{array}$ & $\begin{array}{c}0,097 \\
(0,006)\end{array}$ & $\begin{array}{c}0,085 \\
(0,008)\end{array}$ \\
\hline Tecido conjuntivo (kg) & $\begin{array}{c}0,045 \\
(0,001)\end{array}$ & $\begin{array}{c}0,031 \mathrm{~b} \\
(0,003)\end{array}$ & $\begin{array}{c}0,048 a \\
(0,002)\end{array}$ & $\begin{array}{c}0,055 a \\
(0,002)\end{array}$ & $\begin{array}{c}0,050 \mathrm{a} \\
(0,002)\end{array}$ & $\begin{array}{c}0,040 \mathrm{~b} \\
(0,002)\end{array}$ & $\begin{array}{c}0,044 a b \\
(0,003)\end{array}$ & $\begin{array}{c}0,052 a \\
(0,001)\end{array}$ & $\begin{array}{c}0,037 \mathrm{~b} \\
(0,002)\end{array}$ \\
\hline Osso da paleta (kg) & $\begin{array}{c}0,194 \\
(0,006)\end{array}$ & $\begin{array}{c}0,157 b \\
(0,011)\end{array}$ & $\begin{array}{c}0,188 b \\
(0,009)\end{array}$ & $\begin{array}{c}0,237 a \\
(0,009)\end{array}$ & $\begin{array}{c}0,208 \\
(0,009)\end{array}$ & $\begin{array}{c}0,184 \\
(0,010)\end{array}$ & $\begin{array}{c}0,191 \\
(0,010)\end{array}$ & $\begin{array}{c}0,22 \mathrm{a} \\
(0,007)\end{array}$ & $\begin{array}{c}0,17 b \\
(0,009)\end{array}$ \\
\hline Outros (kg) & $\begin{array}{c}0,025 \\
(0,001)\end{array}$ & $\begin{array}{c}0,015 b \\
(0,002)\end{array}$ & $\begin{array}{c}0,031 \mathrm{a} \\
(0,002)\end{array}$ & $\begin{array}{c}0,028 \mathrm{a} \\
(0,002)\end{array}$ & $\begin{array}{c}0,030 \mathrm{a} \\
(0,002)\end{array}$ & $\begin{array}{c}0,022 b \\
(0,002)\end{array}$ & $\begin{array}{l}0,022 b \\
(0,002)\end{array}$ & $\begin{array}{c}0,027 \\
(0,001)\end{array}$ & $\begin{array}{c}0,022 \\
(0,002)\end{array}$ \\
\hline \multicolumn{10}{|l|}{ Composição do lombo } \\
\hline Lombo (kg) & $\begin{array}{c}0,34 \\
(0,011)\end{array}$ & $\begin{array}{c}0,23 \mathrm{~b} \\
(0,022)\end{array}$ & $\begin{array}{c}0,29 b \\
(0,019)\end{array}$ & $\begin{array}{c}0,48 a \\
(0,018)\end{array}$ & $\begin{array}{c}0,38 a \\
(0,018)\end{array}$ & $\begin{array}{c}0,34 \mathrm{ab} \\
(0,019)\end{array}$ & $\begin{array}{c}0,31 b \\
(0,021)\end{array}$ & $\begin{array}{c}0,37 a \\
(0,014)\end{array}$ & $\begin{array}{c}0,31 b \\
(0,018)\end{array}$ \\
\hline Músculo (kg) & $\begin{array}{c}0,112 \\
(0,005)\end{array}$ & $\begin{array}{c}0,082 b \\
(0,010)\end{array}$ & $\begin{array}{c}0,091 b \\
(0,009)\end{array}$ & $\begin{array}{c}0,164 a \\
(0,008)\end{array}$ & $\begin{array}{c}0,125 \\
(0,008)\end{array}$ & $\begin{array}{c}0,106 \\
(0,009)\end{array}$ & $\begin{array}{c}0,106 \\
(0,009)\end{array}$ & $\begin{array}{c}0,124 a \\
(0,006)\end{array}$ & $\begin{array}{c}0,100 \mathrm{~b} \\
(0,008)\end{array}$ \\
\hline Gordura subcutânea (kg) & $\begin{array}{c}0,018 \\
(0,001)\end{array}$ & $\begin{array}{c}0,013 \mathrm{~b} \\
(0,003)\end{array}$ & $\begin{array}{c}0,014 b \\
(0,002)\end{array}$ & $\begin{array}{c}0,028 \mathrm{a} \\
(0,002)\end{array}$ & $\begin{array}{c}0,018 \\
(0,002)\end{array}$ & $\begin{array}{c}0,017 \\
(0,002)\end{array}$ & $\begin{array}{c}0,019 \\
(0,002)\end{array}$ & $\begin{array}{c}0,016 \\
(0,001)\end{array}$ & $\begin{array}{c}0,021 \\
(0,002)\end{array}$ \\
\hline Gordura intermuscular (kg) & $\begin{array}{c}0,011 \\
(0,0008)\end{array}$ & $\begin{array}{l}0,007 b \\
(0,001)\end{array}$ & $\begin{array}{c}0,010 \mathrm{~b} \\
(0,001)\end{array}$ & $\begin{array}{c}0,017 \mathrm{a} \\
(0,001)\end{array}$ & $\begin{array}{c}0,011 \\
(0,001)\end{array}$ & $\begin{array}{c}0,010 \\
(0,001)\end{array}$ & $\begin{array}{c}0,012 \\
(0,001)\end{array}$ & $\begin{array}{c}0,011 \\
(0,001)\end{array}$ & $\begin{array}{c}0,012 \\
(0,001)\end{array}$ \\
\hline Tecido conjuntivo (kg) & $\begin{array}{c}0,015 \\
(0,0007)\end{array}$ & $\begin{array}{l}0,010 \mathrm{~b} \\
(0,001)\end{array}$ & $\begin{array}{c}0,013 \mathrm{~b} \\
(0,001)\end{array}$ & $\begin{array}{l}0,021 \mathrm{a} \\
(0,001)\end{array}$ & $\begin{array}{c}0,017 \\
(0,001)\end{array}$ & $\begin{array}{c}0,015 \\
(0,001)\end{array}$ & $\begin{array}{c}0,013 \\
(0,001)\end{array}$ & $\begin{array}{c}0,017 \mathrm{a} \\
(0,0009)\end{array}$ & $\begin{array}{l}0,013 \mathrm{~b} \\
(0,001)\end{array}$ \\
\hline Osso (kg) & $\begin{array}{c}0,056 \\
(0,003)\end{array}$ & $\begin{array}{c}0,034 \mathrm{c} \\
(0,006)\end{array}$ & $\begin{array}{c}0,056 b \\
(0,005)\end{array}$ & $\begin{array}{c}0,079 a \\
(0,005)\end{array}$ & $\begin{array}{c}0,070 a \\
(0,005)\end{array}$ & $\begin{array}{l}0,052 \mathrm{ab} \\
(0,005)\end{array}$ & $\begin{array}{c}0,046 b \\
(0,006)\end{array}$ & $\begin{array}{c}0,063 a \\
(0,004)\end{array}$ & $\begin{array}{l}0,049 b \\
(0,005)\end{array}$ \\
\hline Outros (kg) & $\begin{array}{l}0,0094 \\
(0,001)\end{array}$ & $\begin{array}{l}0,0056 \\
(0,002)\end{array}$ & $\begin{array}{l}0,0109 \\
(0,001)\end{array}$ & $\begin{array}{l}0,0117 \\
(0,001)\end{array}$ & $\begin{array}{c}0,0133 a \\
(0,001)\end{array}$ & $\begin{array}{c}0,0087 a b \\
(0,001)\end{array}$ & $\begin{array}{c}0,0061 b \\
(0,002)\end{array}$ & $\begin{array}{l}0,0104 \\
(0,001)\end{array}$ & $\begin{array}{l}0,0084 \\
(0,001)\end{array}$ \\
\hline Gordura perirrenal (kg) & $\begin{array}{l}0,0284 \\
(0,002)\end{array}$ & $\begin{array}{c}0,0184 b \\
(0,004)\end{array}$ & $\begin{array}{c}0,0187 b \\
(0,004)\end{array}$ & $\begin{array}{c}0,0482 \mathrm{a} \\
(0,004)\end{array}$ & $\begin{array}{l}0,0290 \\
(0,004)\end{array}$ & $\begin{array}{l}0,0335 \\
(0,004)\end{array}$ & $\begin{array}{l}0,0228 \\
(0,004)\end{array}$ & $\begin{array}{c}0,0267 \\
(0,003)\end{array}$ & $\begin{array}{c}0,0302 \\
(0,004)\end{array}$ \\
\hline Longissimus dorsi (kg) & $\begin{array}{l}0,0847 \\
(0,002)\end{array}$ & $\begin{array}{l}0,0594 \mathrm{c} \\
(0,005)\end{array}$ & $\begin{array}{c}0,0793 b \\
(0,004)\end{array}$ & $\begin{array}{c}0,1152 \mathrm{a} \\
(0,004)\end{array}$ & $\begin{array}{l}0,0906 \\
(0,004)\end{array}$ & $\begin{array}{l}0,0857 \\
(0,005)\end{array}$ & $\begin{array}{l}0,0776 \\
(0,005)\end{array}$ & $\begin{array}{c}0,0974 a \\
(0,003)\end{array}$ & $\begin{array}{c}0,0718 b \\
(0,004)\end{array}$ \\
\hline Espessura de gordura (mm) & $\begin{array}{c}0,94 \\
(0,067)\end{array}$ & $\begin{array}{c}0,94 \\
(0,130)\end{array}$ & $\begin{array}{c}0,79 \\
(0,110)\end{array}$ & $\begin{array}{c}1,10 \\
(0,104)\end{array}$ & $\begin{array}{c}1,02 \\
(0,106)\end{array}$ & $\begin{array}{c}0,95 \\
(0,114)\end{array}$ & $\begin{array}{c}0,87 \\
(0,123)\end{array}$ & $\begin{array}{c}0,97 \\
(0,084)\end{array}$ & $\begin{array}{c}0,93 \\
(0,105)\end{array}$ \\
\hline
\end{tabular}

Para cada fonte de variação, médias seguidas de mesma letra não diferem $(\mathrm{P}<0,05)$ entre si. 
conjuntivo, gordura renal, osso e outros tecidos, respectivamente (Tabela 8).

Na paleta as porcentagens de músculo e gordura intermuscular aumentaram com a idade. Embora aos 60 e 90 dias não tenha ocorrido diferença para músculo e para gordura intermuscular da paleta, o valor observado aos 90 dias não diferiu dos encontrados aos 60 e 120 dias, fato que pode ser atribuído ao efeito negativo do desaleitamento aos 60 dias, que causou diminuição dos tecidos muscular e adiposo no período de 60-90 dias, com posterior recuperação. As porcentagens de osso e gordura subcutânea diminuíram e essa redução pode ser reflexo do aumento da porcentagem de músculo e gordura intermuscular com a idade, indicando que carcaças mais pesadas tendem a acumular mais tecidos moles.

No lombo, a porcentagem de osso foi maior aos $90 \mathrm{em}$ relação a 60 e os valores não diferiram do obtido aos 120 dias, fato que pode também ser atribuído ao desaleitamento aos 60 dias, que provocou redução na porcentagem de gordura perirrenal e músculo do lombo (Tabela 8).
De modo geral, os Alpinos apresentaram maior porcentagem de tecido conjuntivo e outros tecidos na paleta, e de osso e outros tecidos no lombo em relação aos mestiços, ou seja, menor porcentagem de tecidos nãocomestíveis na carcaça, o que indica menor deposição de tecidos nobres. O percentual de gordura perirenal foi maior nas fêmeas que nos machos.

O peso médio do músculo Longissimus dorsi antes do cozimento aumentou linearmente com a idade (Tabela 9). A média de perda por cozimento do músculo Longissimus dorsi foi de 7,39\% e não foi influenciada pelo grupo racial, semelhante ao observado por Hoffman et al. (2003) ao avaliarem o músculo Longissimus dorsi em cordeiros.

A força de cisalhamento também não diferiu entre os grupos raciais, fato constatado também por Johnson et al. (1995). Entretanto, os resultados foram contrários obtidos por Hoffman et al. (2003) em trabalho com cordeiros e Dhanda et al. (2003), que observaram menor valor de força de cisalhamento para mestiços Boer. A idade também não influenciou a maciez da carne, o que pode estar relacionado

Tabela 8 - Porcentagem tecidual da paleta e do lombo em cabritos machos e fêmeas de três grupos raciais abatidos em diversas idades

\begin{tabular}{|c|c|c|c|c|c|c|c|c|c|}
\hline & Média & \multicolumn{3}{|c|}{ Idade } & \multicolumn{3}{|c|}{ Grupo racial } & \multicolumn{2}{|c|}{ Sexo } \\
\hline \multicolumn{10}{|l|}{ Composição da paleta (\%) } \\
\hline Músculo & $\begin{array}{l}58,90 \\
(0,35)\end{array}$ & $\begin{array}{l}57,47 b \\
(0,68)\end{array}$ & $\begin{array}{l}56,98 b \\
(0,58)\end{array}$ & $\begin{array}{l}61,26 a \\
(0,55)\end{array}$ & $\begin{array}{l}57,89 \\
(0,55)\end{array}$ & $\begin{array}{l}59,43 \\
(0,60)\end{array}$ & $\begin{array}{l}58,38 \\
(0,65)\end{array}$ & $\begin{array}{l}58,94 \\
(0,44)\end{array}$ & $\begin{array}{l}58,20 \\
(0,55)\end{array}$ \\
\hline Gordura subcutânea & $\begin{array}{c}1,26 \\
(0,11)\end{array}$ & $\begin{array}{l}1,71 \mathrm{a} \\
(0,21)\end{array}$ & $\begin{array}{l}0,97 \mathrm{~b} \\
(0,18)\end{array}$ & $\begin{array}{l}1,11 \mathrm{ab} \\
(0,17)\end{array}$ & $\begin{array}{l}1,23 \\
(0,17)\end{array}$ & $\begin{array}{c}1,48 \\
(0,18)\end{array}$ & $\begin{array}{l}1,08 \\
(0,20)\end{array}$ & $\begin{array}{c}1,31 \\
(0,14)\end{array}$ & $\begin{array}{c}1,22 \\
(0,17)\end{array}$ \\
\hline Tecido conjuntivo & $\begin{array}{c}4,54 \\
(0,08)\end{array}$ & $\begin{array}{l}4,31 \mathrm{~b} \\
(0,15)\end{array}$ & $\begin{array}{l}5,04 a \\
(0,13)\end{array}$ & $\begin{array}{l}4,27 \mathrm{~b} \\
(0,12)\end{array}$ & $\begin{array}{l}4,79 a \\
(0,12)\end{array}$ & $\begin{array}{l}4,19 \mathrm{~b} \\
(0,14)\end{array}$ & $\begin{array}{l}4,63 a b \\
(0,15)\end{array}$ & $\begin{array}{c}4,69 \\
(0,09)\end{array}$ & $\begin{array}{c}4,38 \\
(0,12)\end{array}$ \\
\hline Osso & $\begin{array}{l}20,04 \\
(0,26)\end{array}$ & $\begin{array}{l}21,65 a \\
(0,51)\end{array}$ & $\begin{array}{l}20,04 \mathrm{~b} \\
(0,43)\end{array}$ & $\begin{array}{l}18,44 \mathrm{c} \\
(0,41)\end{array}$ & $\begin{array}{l}20,36 \\
(0,41)\end{array}$ & $\begin{array}{l}19,52 \\
(0,45)\end{array}$ & $\begin{array}{l}20,26 \\
(0,48)\end{array}$ & $\begin{array}{l}20,08 \\
(0,33)\end{array}$ & $\begin{array}{l}20,01 \\
(0,41)\end{array}$ \\
\hline Outros & $\begin{array}{c}2,49 \\
(0,10)\end{array}$ & $\begin{array}{l}2,13 b \\
(0,20)\end{array}$ & $\begin{array}{l}3,22 \mathrm{a} \\
(0,17)\end{array}$ & $\begin{array}{l}2,18 b \\
(0,16)\end{array}$ & $\begin{array}{l}2,97 a \\
(0,16)\end{array}$ & $\begin{array}{l}2,27 \mathrm{~b} \\
(0,18)\end{array}$ & $\begin{array}{l}2,28 b \\
(0,19)\end{array}$ & $\begin{array}{c}2,42 \\
(0,13)\end{array}$ & $\begin{array}{c}2,60 \\
(0,16)\end{array}$ \\
\hline Longissimus dorsi & $\begin{array}{l}25,50 \\
(0,67)\end{array}$ & $\begin{array}{l}26,19 \\
(1,31)\end{array}$ & $\begin{array}{l}26,43 \\
(1,11)\end{array}$ & $\begin{array}{l}23,87 \\
(1,04)\end{array}$ & $\begin{array}{l}24,47 \\
(1,06)\end{array}$ & $\begin{array}{l}26,22 \\
(1,15)\end{array}$ & $\begin{array}{l}25,80 \\
(1,24)\end{array}$ & $\begin{array}{l}26,69 \\
(0,85)\end{array}$ & $\begin{array}{l}24,30 \\
(1,06)\end{array}$ \\
\hline $\begin{array}{l}\text { Músculo + Longissimus } \\
\text { dorsi }\end{array}$ & $\begin{array}{l}58,93 \\
(0,95)\end{array}$ & $\begin{array}{l}62,03 \\
(1,84)\end{array}$ & $\begin{array}{l}57,39 \\
(1,57)\end{array}$ & $\begin{array}{l}57,37 \\
(1,47)\end{array}$ & $\begin{array}{l}57,00 \\
(1,49)\end{array}$ & $\begin{array}{l}58,46 \\
(1,61)\end{array}$ & $\begin{array}{l}61,33 \\
(1,74)\end{array}$ & $\begin{array}{l}59,73 \\
(1,19)\end{array}$ & $\begin{array}{l}58,13 \\
(1,49)\end{array}$ \\
\hline Gordura subcutânea & $\begin{array}{l}15,99 \\
(1,22)\end{array}$ & $\begin{array}{l}13,98 \\
(2,37)\end{array}$ & $\begin{array}{l}15,98 \\
(2,01)\end{array}$ & $\begin{array}{l}18,03 \\
(1,89)\end{array}$ & $\begin{array}{l}14,16 \\
(1,92)\end{array}$ & $\begin{array}{l}16,26 \\
(2,08)\end{array}$ & $\begin{array}{l}17,56 \\
(2,24)\end{array}$ & $\begin{array}{l}13,84 \\
(1,53)\end{array}$ & $\begin{array}{l}18,15 \\
(1,91)\end{array}$ \\
\hline Gordura intermuscular & $\begin{array}{c}3,28 \\
(0,23)\end{array}$ & $\begin{array}{c}2,83 \\
(0,44)\end{array}$ & $\begin{array}{c}3,40 \\
(0,37)\end{array}$ & $\begin{array}{c}3,61 \\
(0,35)\end{array}$ & $\begin{array}{c}2,87 \\
(0,36)\end{array}$ & $\begin{array}{c}3,09 \\
(0,38)\end{array}$ & $\begin{array}{c}3,88 \\
(0,42)\end{array}$ & $\begin{array}{c}2,90 \\
(0,28)\end{array}$ & $\begin{array}{c}3,66 \\
(0,36)\end{array}$ \\
\hline Tecido conjuntivo & $\begin{array}{c}4,31 \\
(0,16)\end{array}$ & $\begin{array}{c}4,27 \\
(0,31)\end{array}$ & $\begin{array}{c}4,29 \\
(0,26)\end{array}$ & $\begin{array}{c}4,39 \\
(0,25)\end{array}$ & $\begin{array}{c}4,43 \\
(0,25)\end{array}$ & $\begin{array}{c}4,41 \\
(0,27)\end{array}$ & $\begin{array}{c}4,09 \\
(0,29)\end{array}$ & $\begin{array}{c}4,41 \\
(0,20)\end{array}$ & $\begin{array}{c}4,22 \\
(0,25)\end{array}$ \\
\hline Osso & $\begin{array}{l}16,13 \\
(0,66)\end{array}$ & $\begin{array}{l}13,65 b \\
(1,28)\end{array}$ & $\begin{array}{c}18,73 a \\
(1,09)\end{array}$ & $\begin{array}{c}15,99 a b \\
(1,03)\end{array}$ & $\begin{array}{c}18,78 \mathrm{a} \\
(1,04)\end{array}$ & $\begin{array}{c}14,89 b \\
(1,12)\end{array}$ & $\begin{array}{l}14,71 b \\
(1,21)\end{array}$ & $\begin{array}{l}16,48 \\
(0,83)\end{array}$ & $\begin{array}{l}15,78 \\
(1,04)\end{array}$ \\
\hline Outros & $\begin{array}{c}2,65 \\
(0,25)\end{array}$ & $\begin{array}{l}2,12 b \\
(0,48)\end{array}$ & $\begin{array}{l}3,51 \mathrm{a} \\
(0,41)\end{array}$ & $\begin{array}{c}2,32 b \\
(0,38)\end{array}$ & $\begin{array}{l}3,62 \mathrm{a} \\
(0,39)\end{array}$ & $\begin{array}{l}2,45 a b \\
(0,42)\end{array}$ & $\begin{array}{l}1,89 \mathrm{~b} \\
(0,45)\end{array}$ & $\begin{array}{c}2,72 \\
(0,31)\end{array}$ & $\begin{array}{c}2,58 \\
(0,38)\end{array}$ \\
\hline
\end{tabular}

Para cada fonte de variação, médias seguidas de mesma letra não diferem $(P<0,05)$ entre si. 
Tabela 9 - Peso das amostras de Longissimus dorsi e força de cisalhamento da carne de cabritos machos e fêmeas de três grupos raciais abatidos em diversas idades

\begin{tabular}{|c|c|c|c|c|c|c|c|c|c|}
\hline \multirow[b]{2}{*}{ Característica } & \multirow[b]{2}{*}{ Média } & \multicolumn{3}{|c|}{ Idade } & \multicolumn{3}{|c|}{ Grupo racial } & \multicolumn{2}{|c|}{ Sexo } \\
\hline & & 60 & 90 & 120 & Alpino & $1 / 2$ Boer & 3/4 Boer & Macho & Fêmea \\
\hline Longissimus dorsi (kg) & $\begin{array}{l}0,0771 \\
(0,002)\end{array}$ & $\begin{array}{l}0,0532 \mathrm{c} \\
(0,005)\end{array}$ & $\begin{array}{c}0,0709 b \\
(0,004)\end{array}$ & $\begin{array}{c}0,1071 \mathrm{a} \\
(0,004)\end{array}$ & $\begin{array}{c}0,0812 \\
(0,004)\end{array}$ & $\begin{array}{c}0,0779 \\
(0,004)\end{array}$ & $\begin{array}{c}0,0722 \\
(0,004)\end{array}$ & $\begin{array}{c}0,0894 a \\
(0,003)\end{array}$ & $\begin{array}{c}0,0647 b \\
(0,004)\end{array}$ \\
\hline Força de cisalhamento & $\begin{array}{c}3,46 \\
(0,09)\end{array}$ & $\begin{array}{c}3,76 \\
(0,18)\end{array}$ & $\begin{array}{c}3,34 \\
(0,15)\end{array}$ & $\begin{array}{c}3,28 \\
(0,15)\end{array}$ & $\begin{array}{c}3,58 \\
(0,15)\end{array}$ & $\begin{array}{c}3,67 \\
(0,16)\end{array}$ & $\begin{array}{c}3,12 \\
(0,17)\end{array}$ & $\begin{array}{c}3,33 \\
(0,12)\end{array}$ & $\begin{array}{c}3,59 \\
(0,15)\end{array}$ \\
\hline
\end{tabular}

Para cada fonte de variação, médias seguidas de mesma letra não diferem $(\mathrm{P}<0,05)$ entre si.

ao abate precoce dos animais e também à diferença entre as idades de abate, que foi pequena.

\section{Conclusões}

O avanço da idade de abate dos cabritos implica aumento do peso vivo e dos valores de todas as características da carcaça, dos cortes, do rendimento comercial e dos índices de compacidade da perna e da carcaça. A possível razão para a redução na cobertura de gordura, no rendimento comercial, no índice de compacidade da perna, na porcentagem de músculo e gordura subcutânea da paleta, renal e no aumento da porcentagem de osso no lombo no período entre 60 e 90 dias pode ser o efeito do estresse do desmame aos 60 dias. Os mestiços Boer têm maior compacidade de perna e menos osso em relação aos Alpinos, que apresentam carcaças mais compridas, reduzindo a diferença no rendimento da carcaça.

\section{Literatura Citada}

AMIN, M.R.; HUSAIN, S.S.; ISLAN, A.B.M.M. Evaluation of Black Bengal goats an their cross with the Jamunapari breed for carcass characteristics. Small Ruminant Research, v.38, p.211-215, 2000.

ARGUELlO, A.; CAPOTE, J.; GINÉS, R. et al. Prediction of kid carcass composition by use of joint dissection. Livestock Production Science, v.67, p.293-295, 2001.

BUENO, M.S.; SANTOS, L.E.; CUNHA, E.A. et al. Avaliação de carcaças de cabritos com diferentes pesos vivos. Boletim da Indústria Animal, v.54, p.61-67, 1997.

COLOMER-ROCHER, F.C.; MORAND-FEHR, P.; KIRTON, A.H. Standard methods and procedures for goat carcass evaluation, jointing and tissue separation. Livestock Production Science, v.17, p.149-159, 1987.

DHANDA, J.S.; TAYLOR, D.G.; MC COSKER, J.E. et al. The influence of goat genotype on the production of Capretto and Chevon carcasses. 1- Growth and carcass characteristics. Meat Science, v.52, p.355-361, 1999.

DHANDA, J.S.; TAYLOR, D.G.; MURRAY, P.J. Part 1. Growth, carcass and meat quality parameters of male goats: effects of genotype and liveweight at slaughter. Small Ruminant Research, v.50, p.57-66, 2003.

GOONEWARDENE, L.A.; DAY, P.A.; PATRICK, N. et al. A Preliminary evaluation of growth and carcass traits in Alpine and Boer goat crosses. Journal of Animal Science, v.78, p.229-232, 1998.

HOFFMAN, L.C.; MULLER, M.; CLOETE, S.W. et al. Comparison of six crossbred lamb types: sensory, physical and nutritional meat quality characteristics. Meat Science, v.65, p.1265-1274, 2003.

JOHNSON, D.D.; MC GONAN, C.H.; NURSE, G. et al. R. Breed type and sex effects on carcass traits, composition and tenderness of young goats. Small Ruminant Research, v.17, p.57-63, 1995.

KADIM, I.T.; MAHGOUB, O.; AL-AJMI, D.S. et al. An evaluation of the growth, carcass and meat quality characteristics of Omani goat breeds. Meat Science, v.66, p.203-210, 2003.

MADRUGA, M.S.; ARRUDA, S.G.B.; NASCIMENTO, J.A. Castration and slaughter age effects on nutritive value of the "mestiço" goat meat. Meat Science, v.52, p.119-125, 1999.

MAHGOUB, O.; LODGE, G.A. Growth and body composition in meat production of Omani Batina goats. Smal Ruminante Research, v.19, p.233-246, 1996.

MAHGOUB, O.; LU, C.D. Growth, body composition and carcass tissue distribution in goats of large and small sizes. Small Ruminant Research, v.27, p.267-278, 1998.

MAHGOUB, O.; KADIM, I.T.; AL-SAQRI, N.M. et al. Effects of body weight and sex on carcass tissue distribution in goats. Meat Science, v.67, p.577-585, 2004.

MENEZES, J.J.L.; GONÇALVES, H.C.; RIBEIRO, M.S. et al. Desempenho e medidas biométricas de caprinos de diferentes grupos raciais. Revista Brasileira de Zootecnia, v.36, n.3, p.635-642, 2007.

NAUDÉ, R.T.; HOFMEYR, H.S. Goat production. In: MOURAND, M. (Ed.) Meat production. New York: Academic Press, 1981. p.253-283.

NATIONAL RESEARCH COUNCIL - NRC. Nutrient requeriments of goats. Washington, D.C.: National Academy Press, 1981. 91p.

OMAN, J.S.; WALDRON, D.F.; GRIFFIN, D.B. et al. Effect of breed-type and feeding regimen on goat carcass traits. Journal of Animal Science, v.77, p.3215-3218, 1999.

OMAN, J.S.; WALDRON, D.F.; GRIFFIN, O.B. et al. Carcass traits and retail display-life of chops from different goat breed types. Journal of Animal Science, v.78, p.1262-1266, 2000.

OSÓRIO, J.C.S. Estudio de la calidad de canales comercializadas en el tipo ternasco segun la procedencia: bases para la mejora de dicha calidad en Brazil. 1992. 335f. Tese (Doutorado em Veterinária) - Facultad de Veterinaria, Universidad de Zaragoza, Zaragoza, 1992.

PEREIRA FILHO, J.M.; RESENDE, K.T.; TEIXEIRA, I.A.M.A. et al. Características de carcaça e alometria dos tecidos de cabritos F1 Boer x Saanen. Revista Brasileira de Zootecnia, v.37, n.5, p.905-912, 2008.

SCHÖNFELDT, H.C.; NAUDÉ, R.R.; BOK, W. Cooking and juiciness related quality characteristics of goat and sheep meat. Meat Science, v.34, p.381-394, 1993.

SIMELA, L.; NDLOVU, R.L.; SIBANDA, L.M. Carcass characteristics of the marketed matebele goat from south-western. Small Ruminant Research, v.32, p.173-179, 1999. 
TEIXEIRA, A.; AZEVEDO, J.; DELFA, R. Growth and development of Serrana kids from Montesinho Natural Park. Small Ruminant Research, v.16, p.263-269, 1995.

TODARO, M.; CARRAO, A.; BARONE, C.M.A. et al. The influence of age at slaughter and litter size on some quality traits of kid meat. Small Ruminant Research, v.44, p.75-80, 2002.

THWAITES, C.J.; YEATES, N.T.M.; POGUE, R.F. Objective appraisal of intact lamb and muton carcasses. Journal Agriculture Science, v.63, p.415-420, 1964.
UNIVERSIDADE FEDERAL DE VICCOSA - UFV. Sistema de Análise Estatística e Genéticas - SAEG. Versão 9.0. Viçosa, MG, 2000. VAN NIEKERK, W.A.; CASEY, N.H. The Boer goat ll. Growth, nutrient requeriments, carcass and meat quality. Small Ruminant Research, v.1, p.355-368, 1988.

YÁÑEZ, E.A.; RESENDE, K.T.; FERREIRA, A.C.D. et al. Restrição alimentar em caprinos: rendimento, cortes comerciais e composição da carcaça. Revista Brasileira de Zootecnia, v.35, n.5, p.2093-2100, 2006. 